\title{
Phonological Phrasing and Questions in Chimwiini ${ }^{1}$
}

\author{
Charles W. Kisseberth
}

Tel Aviv University (emeritus)

This paper examines how questions, both Wh-questions and yes-no questions, are phrased in Chimwiini, a Bantu language spoken in southern Somalia. Questions do not require any special phrasing principles, but Wh-questions do provide much evidence in support of the principle Align-Foc R, which requires that focused or emphasized words/constituents be located at the end of a phonological phrase. Question words and enclitics are always focused and thus appear at the end of a phrase. Although questions do not require any new phrasing principles, they do display complex accentual (tonal) behavior. This paper attempts to provide an account of these accentual phenomena.

\section{Introduction}

This paper provides a sketch of the phrasing of questions in Chimwiini, both "Wh"-questions and "yes-no" questions.

Chimwiini is a Bantu language, closely related to Swahili, spoken in the town of Brava in southern Somalia. In the 1970's, when we began working on the language, there were about 10,000 speakers, almost all of them residing in Brava. Chimwiini apparently had been the dominant language in Brava for some centuries and Brava's inhabitants (wanthu wa Mwiini 'the people of Mwiini [=Brava]') were part of the "Swahili" culture that had once extended from southern Somalia down to northern Mozambique. However, by the 1970's, a substantial number of Somalis from the surrounding Tunni clans had come to reside in the town; many of these became fluent in Chimwiini. The dominance of Chimwiini began to wane as the government relocated Somalis from other areas to Brava, and then the Somali civil war in the 1990's resulted in the

1 The research in this paper was funded by the National Endowment for the Humanities, grant \#DEL PD-50009 ("Documentation of Chimwiini," principal investigator: Prof. Brent Henderson) as part of their program "Documenting Endangered Languages". My thanks both to the NEH and to Brent Henderson. 
murder, pillaging, and rape of the wanthu wa Mwiini, forcing many to flee to Kenya and beyond. At the present time, there are significant communities of Chimwiini speakers in Kenya, the United Kingdom, the United States, and elsewhere.

Although Chimwiini is very closely related to Swahili, it is radically different from it in its prosody. It is the prosody of Chimwiini that forces one to conclude that Chimwiini sentences are exhaustively parsed into a sequence of phonological phrases. In this paper, we assume familiarity with the general issue of phrasing in Chimwiini, only summarizing the main outlines in the next section. For extensive background see Kisseberth (2005, 2010a, 2010b) and Kisseberth and Abasheikh (1974, 2004, in press). See Selkirk (1986) for the first attempt to formulate a theory of Chimwiini phrasing.

Our focus here is the formation of questions in Chimwiini. Once it is understood that the Wh-question words/enclitics are categorized as [+Focus], then there are really no special attributes to the phrasing of questions that would distinguish them from statements. But this does not mean that questions are not of great interest for the phonology of phrasing in Chimwiini. As we will see, phonological phrasing in Chimwiini determines two separate prosodic systems: vowel length and accent. Although questions do not have any notable special characteristics when it comes to vowel length, they do have considerable accentual effects. It is these effects that we will be surveying.

\section{Preliminaries}

There are two prosodic principles in Chimwiini whose scope of application is the phonological phrase. One of these systems involve an abstract stress that is assigned according to the Latin Stress Rule. Specifically, it stresses the penult syllable in the phonological phrase if it is heavy (i.e. has a bimoraic vowel or a coda consonant), and if the penult is not heavy but there is an antepenult syllable, then stress falls on the antepenult, regardless of weight. If there is no antepenult syllable, then stress falls on the penult regardless of weight. The only overt manifestation of this stress is the distribution of long vowels: a long vowel can be realized as long just in case it is located in a stressed syllable. A vowel that is underlyingly long or would be lengthened by general rule will be short if in an unstressed syllable. One can often determine the phrasing of a sentence by observing where long vowels surface and where expected long vowels fail to surface. But in the absence of (expected) long vowels, one cannot be certain of the phrasing if it is only vowel quantity that is taken into account.

Fortunately, there is a second prosodic system that always provides reliable evidence for the phrasing of a sentence. Each phonological phrase bears a single accent (realized as High tone). This accent always resides on the final prosodic 
word in the phrase. In certain morphosyntactic environments, this accent is on the final syllable of the word. In the default case, it is on the penult syllable. If the prosodic word consists of a single syllable, then there is no contrast and the only available syllable is accented.

Final-accent triggers in Chimwiini include:

- First and second person subject forms in the present and past tense (in contrast to the third person subject forms where default accent prevails).

- Relative clauses.

- The conditional $\boldsymbol{k} \boldsymbol{a}$ tense regardless of the nature of the subject prefix.

- The conjunction na 'and'.

- Certain lexical items.

If there is a final accent trigger in a phrase, then final accent appears on the last word in the phrase. If the accent in a phrase is the default penult accent, then it is the final word in the phrase that bears this accent.

The phrases that determine where abstract stress is located are exactly the same phrases that determine whether a word bears an accent or not. In other words, these two independent phonological phenomena operate in precisely the same phrases. The critical issue, of course, is how are these phrases determined? Does a sentence have just one possible phrasing, or are alternative phrasings available?

The two foremost principles of phrase formation are:

(1) ALIGN-XP-R

Align the right edge of every (lexical) maximal projection with the right edge of a Phonological Phrase (=PP).

(2) Align-FocR

Align the right edge of every focused (alternatively: emphasized) element with the right edge of a PP.

A third constraint is given as (3):

(3) ALIGN-VERB ${ }_{\mathrm{NEG}} \mathrm{R}$

Align the right edge right edge of a negative verb with the right edge of a PP.

One might argue that a negative verb is inherently focused, and thus (3) is simply a subcase of (2). A deeper look at the data shows that this inherent focus may be overridden, in which case the negative verb is not necessarily at the end of a PP. 
There are some additional phrasing constraints - (a) particles that cannot be joined with other words at one or both edges; (b) special phrasings of modifiers connected to the definite/indefinite contrast; (c) variations in the phrasing of associative phrases and restructuring of these phrases when they have a possessive use - but we will not be discussing these here.

With this much background, we can turn to the matter of the phrasing of questions in Chimwiini.

\section{Wh-questions and their phrasing}

The effect of Wh-questions on phonological phrasing is in part easily expressed: a Wh-question word or enclitic element always stands at the end of a phonological phrase. This indicates that the question word or enclitic is [+Focus], and that Align-FocR (cf. (2) above) is at play. Other than this, Whquestions do not raise any particular issues regarding phrasing. They do, however raise some significant issues with respect to the accentual system that works on the phrasing in a sentence. Specifically, under certain circumstances Wh-words trigger what we refer to as the pseudo-relativization of the verb. By this we mean that the verb assumes the overt shape of a relative verb: namely, in the case of active, affirmative tenses, a final vowel -o, and in all tenses, the relative verb is a final-accent trigger. As we shall see, the behavior of accent in pseudo-relatives is not the same as in true relatives.

\subsection{Naani-questions}

We begin our discussion with the question word naani 'who(m)'. Naani may occur in pre-verbal subject position, in which case the main verb is necessarily put into a pseudo-relative form. (4) illustrates extremely simple sentences where the VP consists of just a verb. ${ }^{2}$

2 A few words concerning the transcription and glossing of sentences are in order. There are five vowels $-\mathbf{i}, \mathbf{u}, \mathbf{e}, \mathbf{o}, \mathbf{a}-$ which appear both short and long. The long vowels are written with the vowel symbol repeated: ii, uu, oo, etc. Accent is indicated by an acute mark over the vowel. The transcription of consonants is irrelevant to this paper and will not be discussed. In the transcription, we separate prefixes from what follows by a hyphen; enclitics are separated from the preceding word by the symbol "=". We do not indicate the internal structure of the verb stem, due to its complexity. Second person singular and human third person singular subject prefixes are phonologically null in affirmative tenses, and we indicate such null prefixes by the symbol " $\varnothing$ ". The line below the example provides a word by word gloss. Only the structure of the verb is shown: each prefix is indicated by abbreviations like "SP” (subject prefix), “OP” (object prefix), "pres” (present tense marker), "fut” (future tense marker), "inf” (infinitive), "hab” (habitual), "cont” (continuous), "cond" (conditional), "neg” (negative). Each prefix is followed by a hyphen. The verb stem is glossed by the relevant English verb, and in parentheses after this verb 
(4)

a. náani/ Ø-kodheeló

who/ SP-speak (perf, rel)

'Who spoke?'

b. náani/ nth-a-kh-koodhá

who/ neg-SP-inf-speak

'Who did not speak?'

c. náani/ Ø-pishiló

who/ SP-cook (perf, rel)

'Who cooked?'

d. náani/ Ø-tagamanishiizó

who/ SP-stretch (perf, rel)

'Who stretched it (e.g. he did a good job, it is fully taut)?'

e. mw-ana w-a náani/ Ø-iló

child of whom/ SP-come (perf, rel)

'Whose child came?'

It is obvious from the final $\boldsymbol{o}$ vowel and the final accent that the verb in these examples has the shape of a relative clause. The question word naani bears an accent and retains its lexical long vowel. These two facts indicate that naani is in a separate phrase from the pseudo-relative verb. This phrasal separation can be attributed to ALIGN-XP R on the basis of the fact that naani is an XP. This same phrasal edge also follows from considering naani to be the focus of the above sentences.

Since naani is the subject of the pseudo-relative verb (or is an element inside the subject as in (4e)), it is natural to ask how the phrasing of these sentences compares to the phrasing of true relatives. When the subject of a true relative clause is preverbal and not the head of the relative clause, then it is obligatorily phrased separately from the relative verb. This can be seen from the examples in (5).

the stem is further classifed as "perf" (perfect) or "pass" (passive) or "rel” (relative) or a combination of these. The third line renders the example into English. 
(5)

a. chi-su ch-aa mí/ n-uuziló

knife that I/ SP-buy (perf, rel)

'the knife that I bought'

b. pesa z-a Núuru/ Ø-khirilo ki-zi-ruudá

money that Nuuru/ SP-agree (perf, rel) inf-OP-return

'the money that Nuuru agreed to return'

c. n-uzize chi-buku ch-a mw-aaná/ Ø-m-bozelo mw-aalimú

SP-buy (perf) book that child/ SP-OP-steal (perf, rel) teacher

'I bought the book that the child stole from the teacher.'

\section{d. Núuru/ Ø-inenzeze gari ya Háají/ Ø-uziló}

Nuuru/ SP-drive (perf) truck that Haaji/ SP-buy (perf, rel)

'Nuuru drove the truck that Haaji bought.'

The subjects of the pseudo-relative clauses in (4) thus are entirely parallel to those in (5) with regard to their phrasing (and thus can be accounted for in terms of Align-XP R without any necessary reference to focus). While naani in the sentences in (4) always has default penult accent, this is not necessarily the case with respect to the subject of a true relative clause. In (5c), for instance, the subject has final accent due to the fact that it forms part of a phrase containing a final-accent trigger. Further research is required to see whether it is possible for naani in subject position of a question to acquire final accent by virtue of being within the scope of a final-accent trigger. We expect that this is likely.

So far we have only looked at the phrasing of the subject of a relative clause when it is not the head. When it is also the head, then the subject immediately precedes the verb, and it may optionally be phrased with the verb or not, with apparently no particular difference in use.

(6)

head phrased with the verb

a. mu-nthu Ø-ofeto kh-fakatá/ Ø-na-kh-pumúla

man SP-be tired (perf, rel) inf-run/ SP-pres-inf-rest

'the man who is tired from running is resting now'

b. mw-alimu Ø-bozelo chi-buukú/ ni Huséeni

teacher SP-steal (perf, rel) book/ is Huseeni

'the teacher who stole the book is Huseeni' 
c. mu-nthu Ø-na-kh-suloowá/ ni úyu person SP-pres-inf-want (pass)/ is this 'the person who is wanted is this one'

head phrased separately from the verb

d. ni-m-wene mw-aalimú/ Ø-bozelo chi-buku ch-a mw-aaná SP-OP-see (perf) teacher/ SP-steal (perf, rel) book of child 'I saw the teacher who stole the child's book'

e. n-thále/ i-laziló/ ha-y-rúudi/ chi-núme arrow/ SP-leave (perf, rel)/ neg-SP-return/ back 'an arrow/ that has left/ does not return/ back'

\section{f. múu-nthu/ Ø-na-kh-suloowá/ ni úyu}

person/ SP-pres-inf-want (pass)/ is this 'the person/ who is wanted/ is this one'

It remains to be seen how free this variation in phrasing is, but for our present purposes it is just important to point out that in the pseudo-relative case, we have not observed any variation: the subject has always been separated from the pseudo-relative verb. This lack of parallelism between (4) and subjectrelativization could conceivably be attributed to the focused nature of naani, but it could be taken instead to be evidence that unlike a true relative, a pseudorelative is not modifying a head at all. Under that interpretation, the variation in (6) involves an aspect of modification.

Let us now return to the behavior of naani. In the examples in (7), the pseudo-relative verb has a complement (in contrast to (4) above). The pseudorelative verb, being a final-accent trigger, projects its final accent to the end of the complement.

a. náani/ Ø-ilo gowolii=ní

who/ SP-come (perf, rel) meeting=loc

'who/ came to the meeting?'

b. náani/ Ø-tumila Mkhodiishó

who/ SP-send (perf, pass, rel) Mogadisho

'who/ was sent to Mogadisho?' 
c. náani/ Ø-uzilo chi-buukú who/ SP-buy (perf, rel) book 'who bought the book?'

d. náani/ Ø-fuziloo n-guwó who/ SP-wash (perf, rel) clothes 'who washed clothes?'

e. náani/ Ø-vunzilo m-laangó who/ SP-break (perf, rel) door 'who broke down the door?'

\section{f. náani/ h-a-torati chii-nthú} who/ neg-SP-be able thing 'who is not able to do anything?'

\section{g. náani/ Ø-na-kh-sulo k-ula chi-ta ch-a n-goombé} who/ SP-pres-inf-want (perf, rel) inf-buy head of cow 'who wants to buy the head of a cow?'

These examples illustrate first of all that a pseudo-relative verb behaves like any other verb in that it does not necessarily occur at the end of a PP. Second, these examples illustrate the general fact that when a verb triggers final accent, this accent does not occur necessarily on the verb but rather at the end of the phonological phrase that contains the verb.

In the examples in (8), the pseudo-relative verb is followed by two XP's. In these examples, naani is the subject of the verb and stands in PP-final position because it is at the end of an XP (and possibly also because it is [+Foc], but this has not yet been conclusively established). The verb, not being focused, is joined together with its immediately following complement into a phrase as a consequence of the Align-XP R principle. The second complement forms its own phrase as a consequence of Align-XP $\mathrm{R}$ as well. The final accent of the verb occurs at the end of each PP.

a. náani/ Ø-pela chibuukú/ na mwaalimú who/ SP-give (perf, pass, rel) book/ by teacher 'who was given a book by the teacher?' 
b. náani/ Ø-latililo i-ji-wé/ ch-olokoo=ní

who/ SP-throw (perf, rel) stone/ window=loc

'who threw a stone at the window?'

c. náani/ Ø-weshelo zi-buukú/ nthini y-a meezá

who/ SP-put (perf, rel) books/ under of table

'who put the books under the table?'

d. náani/ Ø-m-bozelo mw-aalimú/ chi-buukú

who/ SP-OP-steal (perf, rel) teacher/ book

'who stole from the teacher a book?'

e. náani/ Ø-m-tindililio mw-aaná/ namá

who/ SP-OP-cut (perf, rel) child/ meat

'who cut for the child meat?'

The pseudo-relative verb phrases in (8) reveal the same phrasing as in nonrelative verb phrase, as shown in (9). Specifically, there is a phrase break between the first and second complement to the verb. Of course, in non-relative sentences, the accent is default accent unless the verb is a final-accent trigger.

(9)

a. Omári/ Ø-pela chibúuku/ na mwaalímu

Omari/ SP-give (perf, pass) book/ by teacher

'Omari was given a book by the teacher.'

b. mw-áana/ Ø-latilile i-jí-we/ ch-olokóo=ni

child/ SP-throw (perf) stone/ window=loc

'The child/ threw a stone/ at the window.'

c. Hamádi/ Ø-weshele zi-búuku/ nthini y-a méeza

Hamadi/ SP-put (perf) books/ under of table

'Hamadi put the books under the table.'

d. ni-m-tindilile mw-aaná/ namá

SP-OP-cut for (perf) child/ meat

'I cut meat for the child.'

However, there is one significant fact about the accent in non-relative verb phrases that must be discussed. Specifically, if the verb or some VP-internal 
complement is focused, then final accent does not project past the focused element.

(10)

a. no focus: ni-m-bozele mw-aaná/ chi-buukú

SP-OP-steal (perf) child/ book

'I stole from the child/ a book'

b. verb focus: ni-m-boozelé/ mw-áana/ chi-búuku

SP-OP-steal (perf)/ child/ book

'I stole from the child a book'

c. focus mw-aana ni-m-bozele mw-aaná/ chi-búuku

SP-OP-steal (perf) child/ book

These data illustrate what we call the ACCENTUAL LAW OF FocUS:

(11) AcCentual Law of Focus

A focused element does not allow the projection of final accent across it.

In (10b) the verb is focused and thus final accent resides on the verb and not on either of the following complements. In (10c) it is the first complement that is focused, and thus final accent resides on it and not on the second complement. In contrast, there is no focus in (10a) and thus final accent occurs at the end of both complements.

These data raise two significant questions. What is the formal analysis of why final accent appears at the end of both phrases in (10a)? And what is the formal analysis of the Accentual Law of Focus? Why is it the case that when there is focus the final accent is not extended further? We have suggested elsewhere (see, for example, Kisseberth and Abasheikh (in press)) an account that uses a more complex phrasing structure (specifically, recursive phrasing) and a reformulated ALIGN-FOC R constraint to predict these accentual facts. Discussion of this analysis is beyond the immediate concerns of this paper.

Having seen how the Accentual Law of Focus works in non-relative clauses, let us turn to the case of pseudo-relativization (as seen in naani questions).

The pseudo-relative verb may be focused, in which case it is at the end of a PP. 
(12)

a. náani/ Ø-someeló/ chi-búuku

who/ SP-read (perf, rel)/ book

'who/ read/ the book?'

(cf., without focus, náani/ Ø-somelo chibuukú 'who read the book?')

b. náani/ Ø-uziló/ chi-búuku

who/ SP-buy (perf,rel) book

'who/ bought/ the book?'

(cf., without focus, náani/ Ø-uzilo chibuukú 'who bought the book?’)

c. náani/ Ø-ta-k-uuló/ fatuura

who/ SP-fut-inf-buy (rel)/ car

'who/ will buy/ a car?'

(cf., without focus, náani/ ta-k-ulo fatuurá ‘who will buy a car?’)

d. náani/ Ø-tumiilá/ Mkhodíisho

who/ SP-send (perf, pass, rel)

'who was sent to Mogadisho?'

(cf., without focus, náani/ tumila Mkhodiishó

'who was sent to Mogadisho?')

What we see from these data is that when the verb is focused, it remains a final accent trigger, but the complement is outside the scope of the final accent. A pronunciation like *náani/ Ø-ta-k-uuló/ fatuurá 'who/ bought/ a car?' is apparently not acceptable, at least in the typical intonation (there seem to be intonational uses of a shift to final accent that we do not at present entirely understand, thus we hesitate to say categorically that final accent is impossible).

From (12), we can conclude that the pseudo-relativized verb is controlled by the ACCENTUAL LAW OF FocUs. This contrasts, however, with the behavior of a true relative clause, where even in the presence of verb focus, the entire relative clause is in the scope of the final accent.

a. mw-áana/ Ø-uziizó/ chi-buukú

child/ SP-sell (perf, rel)/ book

'the child who sold a book'

b. múu-nthu/ Ø-m-weenó/ mw-iizí

person/ SP-OP-see (perf, rel)/ thief

'the person who saw the thief' 


\section{c. mu-ke nth-a-m-fulilá/ mw-aaná/ n-guwó/ ni Haliima woman neg-SP-OP-wash for (perf, rel)/ child/ clothes/ is Haliima 'The woman who did not wash for the child clothes is Haliima.'}

The difference between (12) and (13) indicates that there must be a difference between pseudo-relative clauses and true relative clauses. We believe that the analysis of this difference may revolve around true relative clauses ranking ALIGN-FOCR below the constraint WRAP-XP (a constraint suggested in Truckenbrodt (1999) that plays a critical role in our account of the Accentual Law of Focus), while pseudo-relative clauses and non-relative clauses have the opposite ranking. This is speculative, however, and outside the scope of this paper.

So far, all of our examples have involved naani being located in pre-verbal position without any other pre-verbal elements. But it is possible for more complex structures to occur.

\section{(14) náani/ m-láango/ Ø-fungiiló \\ who/ door/ SP-open (perf, rel) \\ 'who opened the door?'}

In this example, naani is again at the end of a PP both because it is an XP (and perhaps also because is is [+Foc]). It is followed by a preposed complement, which is an XP and thus forms a PP. The verb is also an XP and forms a PP. The verb is in pseudo-relative form. No special comment is required.

In the preceding examples, naani functions as the subject of the verb and occupies a pre-verbal position. It is not the case, however, that it is only when naani is a preverbal subject that we get the pseudo-relative form of the verb. Consider the following example:

a. chi-buku ch-a náani/ Ø-peetó

book of who/ SP-find (perf, rel)

'whose book did you find?'

b. náani/ w-a Omári/ Ø-m-bozelo chi-buukú who/ that Omari/ SP-OP-steal (perf, rel) book 'who was it that Omari stole a book from?'

In (15a), the object chi-buku ch-a naani is preposed to sentence-initial position. The verb is in pseudo-relative form. In (15b), the question word naani is 
questioning a complement of the verb, but it has been preposed to sentenceinitial position. In this position, it requires the same morphology as does a true relative clause whose head is not the subject. Specifically, naani is linked by the $\boldsymbol{A G}$-a particle to the subject of the verb. Given this pattern, then examples like (15b) support the analysis that naani is a [+Foc] element. Ordinarily, as shown in (5) above, the non-subject head of a relative groups phrasally with the $\boldsymbol{A} \boldsymbol{G}-\boldsymbol{a}$ NP structure. But in (15b), naani does not group with $\boldsymbol{w}$-a Omari. If this is indeed a necessary aspect of the behavior of naani, as we believe, then we have clear evidence that naani is focused.

When naani is post-verbal and not a subject, the verb is not in the pseudorelative form.

a. chi-buku íchi/ n-chha náani

book this/ is-of who

'this book is whose?'

b. Múusa/ Ø-m-bozele náani/ chi-búuku

Muusa/ SP-OP-steal (perf) who/ book

'Muusa stole from whom the book?'

c. Jáama/ Ø-m-tindililie náani/ náma

Jaama/ SP-OP-cut for (perf) who/ meat

'for whom did Jaama cut meat?'

d. Ø-m-bigililie naaní/ lúti

SP-OP-hit with who/ stick

'whom did you hit with the stick?'

e. yé/ nth-a-ku-letela náani/ chi-búuku

he/ neg-SP-inf-bring-to who/ book

'to whom did he not bring a book?'

\section{f. Omári/ Ø-m-patililile náani/ gáari}

Omari/ SP-OP-get for (perf) who/ car

'whom did Ali get a car for?'

These data help to sort out the conditions under which the question word naani triggers pseudo-relativization. But (16d) also helps us to establish clearly that naani is [+Foc]. In (16d), the subject is second person singular and thus a finalaccent trigger. This final accent appears on naani, as it would appear on any 
complement to the verb as long as the verb itself is not focused. However, the final accent does not occur on the second complement - *Ø-m-bigilile naaní/ lutí - as would be expected if naani were not focused. Recall that the final accent triggered by a verb ordinarily extends to the final word in each PP in the verb phrase; the only thing that prevents this is a VP-internal focused element. Such elements, at least in non-relative clauses, serves to block the projection of the final accent onto elements to its right. As discussed earlier, we refer to this as the Accentual Law of Focus.

Having established that naani is focused, let us return to the issue of naani and the conditions under which it induces pseudo-relativization. We have seen that naani when pre-verbal triggers pseudo-relativization regardless of whether it is functioning as a subject or an object of the verb. We have also seen that when post-verbal and functioning as an object, naani does not trigger pseudorelativization. The question that arises is what happens if naani is both postverbal and also functioning as the subject of the verb? We do not presently have much data on this point, but the examples that we do have indicate that the verb is not shifted to a pseudo-relative form.

a. Ø-wa-pikililia náani/ máangi

SP-OP-cook for (perf, pass) who/ maangi'

'who (pl.) was cooked maangi for?'

b. Ø-talishiza náani/ zi-búuku

SP-make to take (perf, pass) who/ books

'who was made to take books?'

\section{c. Ø-tumila náani/ Mkhodíisho}

SP-send (perf, pass) who/ Mogadisho

'who was sent to Mogadisho?'

In (17), the postposed naani is phrasally grouped with the verb. Our consultant did not accept the case where a postposed naani is separated phrasally from the preceding verb: *Tumíla/ánáani/ Mkhodíisho. In our data from statements as opposed to questions, we also found that a subject that is postposed to a passive verb is ordinarily phrased with the passive verb. Although the postposing of a subject is by no means confined to passive verbs, it is well attested there in our materials.

We see in (17) that when the question word naani is post-verbal but is also the subject of the verb, it does not trigger the pseudo-relative form of the verb: *Ø-talishiza naaní/ zibúuku. Pseudo-relativization in these examples would be 
signaled by final accent only, due to the fact that a passive verb in the relative form does not change its final vowel to -o but rather appears as it would in the corresponding non-relative version, here $-\boldsymbol{a}$. (It should be noted that an active verb in the perfect has $\boldsymbol{- e}$ as its final vowel while the passive has $-\boldsymbol{a}$.)

We can conclude from the discussion in this section, that pseudorelativization of the verb is dependent entirely on whether naani is located before the verb or after the verb. We have also cited one data type, involving the ACCENTUAL LAW OF FOCUS, that supports the view that naani is [+Foc].

\subsection{Gani-questions}

The next question word that we will examine is gani 'which'. When gani modifies a pre-verbal NP, the verb is put in the pseudo-relative form. The modified noun may be the subject of the sentence, as in (18).

a. chi-buku gáni/ chi-beeló

book which/ SP-be lost (perf, rel)

'which book is lost?'

b. w-ana gáni/ w-a Núuru/ wa-'olosheló

children which/ of Nuuru/ SP-go (perf, rel)

'which children of Nuuru's went?'

We see that in each example, the verb is in a pseudo-relative form (indicated by the final vowel -o and by the final accent). We also see that gani is phrase-final (though it is perhaps worth noting that gani is exceptional in that a $\boldsymbol{C V C V}$ word at the end of a phrase ordinarily induces a lengthening of a preceding word-final vowel. The question that arises is whether gani is phrase-final merely because it is at the end of a XP or whether it is also phrase-final due to being focused. (18a) does not contribute any evidence with respect to this issue, but (18b) supports the view that gani is focused. This example involves questioning inside an associative phrase. The phrase $\mathbf{w}$-ana w-a Núuru is regularly parsed into a single phrase, with $\boldsymbol{w}$-aana 'children' grouping with $\boldsymbol{w}$-a Nuuru. But notice in (18b) that gani is phrase-final (as indicated by the fact that it receives accent). As far as we know, it cannot be phrase-internal: *w-ana gani w-a Núuru. Thus the observed phrasing supports the position that gani is [+Foc].

The noun that gani modifies may be a preposed complement to the verb: 
(19)

a. chi-buku gáni/ karka z-aa wé/ Ø-uziló/ wé/ Ø-someeló

book which/ among that you/ SP-buy (perf, rel)/ you/ SP-read (perf, rel)

'which book among those that you bought have you read?'

b. chi-buku gáni/ Ø-m-pelo m-aaná

book which/ SP-OP-give (perf, rel) child

'which book did you give the child?'

c. chi-buku gáni/ Ø-teto nthini y-a meezá

book which/ SP-take (perf, rel) under of table

'which book did you take from under the table?'

d. ch-a-kuja gáni/ wé/ Ø-na-kh-suuló

food which/ you/ SP-pres-inf-want (perf, rel)

'what food is it that you want?'

e. fatura gáni/ Núuru/ Ø-uziló

car which/ Nuuru/ SP-buy (perf, rel)

'which car did Nuuru buy?'

f. gari y-a lamna gáni/ wé/ Ø-uziló

car of kind which/ you/ SP-buy (perf, rel)

'what kind of car did you buy?'

g. nthini y-a meza gáni/ Ø-weshelo zi-buukú

under of table which/ SP-put (perf, rel) books

'under which table did you put the books?'

It is possible for the verb to be focused as well and thus be in PP-final position.

(20) chi-buku gani/ Ø-teetó/ nthini y-a meeza

book which/ SP-take (perf, rel)/ under of table

'which book did you take from under the table?'

Observe that the complement to the focused verb is outside the scope of the final accent-triggering verb. This example suggests again that the pseudo-relative clause is controlled by the ACCENTUAL LAW OF FocUs. ${ }^{3}$ In contrast, the final

3 However, our consultant considered it possible for the accent to be shifted to the final syllable in $\mathbf{n t}^{\mathrm{h}}$ ini $\mathbf{y}$-a meeza for purposes of emphasis. It is not clear, however, whether 
accent triggered by a true relative clause always extends to the end of the relative clause, even if the verb is emphasized; i.e. the ACCENTUAL LAW OF Focus does not control true relative clauses.

When the NP modified by gani is post-verbal and not a subject, then the verb is not switched to the pseudo-relative form.

a. Ø-uzile gaarí/ lamna ganí

SP-buy (perf) car/ kind which

'you bought what kind of a car?'

b. maamé/ wáawe/ Ø-sh-fanya kazi gáni

my mother/ my father/ SP-cont-do work which

'mother, what kind of work did my father do?'

c. n-thile mandra ganí/ Ø-ka-piya m-konó

SP-put (perf) bread which/ SP-cond-burn hand

'what kind of bread did I put (in the fire) that I burned my hand?'

At this point in our research, we can only say that gani and naani seem to be parallel in that (a) they are focused and (b) they trigger pseudo-relativization only when they are pre-verbal. The verb is in its non-relative shape when gani and naani are post-verbal. Furthermore, the pseudo-relative verb in both cases respects the ACCENTUAL LAW OF FOCUS.

\subsection{Liini-questions}

The third question word is liini 'when'. Once again, in pre-verbal position, liini requires pseudo-relativization.

a. Omári/ líini/ Ø-iló

Omari/ when/ SP-come (perf, rel)

'Omari, when did he come?'

(Or: líini/ Omári/ Ø-iló 'ibid.')

such examples represent an actual violation of the ACCENTUAL LAW OF FOCUS or whether a special assignment of final accent is involved. Only further research will resolve this issue. 
b. líini/ n-jiiló

when/ SP-eat (perf, rel)

'when did I eat?'

c. líini/ Omári/ Ø-iló

when/ Omari/ SP-come (perf, rel)

'when did Omari come?'

Or: Omári/ líini/ Ø-iló.

d. líini/ n-tha-k-eendró

when/ SP-fut-inf-go (rel)

'when will I be going?'

e. líini/ Ø-olosheló

when/ SP-go (perf, rel)

'when did he go?'

f. líini/ Halíima/ Ø-pishiloo zi-jó

when/ Haliima/ SP-cook (perf, rel) zijo

'when did Haliima cook zi-jo?'

g. líini/ ma-políisi/ wa-m-shishilo m-iizí

when/ police/ SP-OP-catch (perf, rel) thief

'when did the police catch the thief?'

h. İíini/ Súufi/ Ø-latilo i-ji-wé/ ch-olokoo=ní

when/ Suufi/ SP-throw (perf, rel) stone/ window=loc

'when did Suufi throw a stone at the window?'

i. líini/ Faatima/ Ø-fuziloo n-guwó

when/ SP-wash (perf, rel) clothes

'when did Faatima wash clothes?'

j. líini/ maskíini/ Ø-bozelo peesá

when/ poor man/ SP-steal (perf, rel) money

'when did the poor man steal money?'

k. líini/ yé/ h-a-ta-kh-fanya kaazí

when/ he/ neg-SP-fut-inf-do work

'when won't he work?' 


\section{1. líini/ Hasáni/ Ø-uzilo faturaa mphiyá}

when/ Hasani/ SP-buy (perf, rel) car new

'when did Hasani buy a new car?'

m. líini/ Núuru/ Ø-uzilo gaarí

when/ Nuuru/ SP-buy (perf, rel) car

'when did Ali buy a car?'

(Observe that although a negative verb is in the default case phrase-final, the pseudo-relative context here puts the complement into the same phrase as the negative verb. This is a general fact: a negative verb in a relative clause is not necessarily phrase-final.)

If liini is post-verbal, the verb is not put into pseudo-relative form.

a. Ø-oloshele líini

SP-go (perf) when

'when did he go?'

b. Omári/ Ø-ile líini

Omari/ SP-come (perf) when

'when did Omari come?'

c. Ø-andishile liiní/ kháti

SP-write (perf) when/ letter

'when did you write a letter?'

d. Ø-na-k-endra liiní/ Mkhodiisho

SP-pres-inf-go when/ Mogadisho

'when are you going to Mogadisho?'

e. n-jile liiní

SP-eat (perf) when

'when did I eat?'

(cf. Ø-jile liiní 'when did you eat?’ Ø-jile líini 'when did he eat?’)

\section{f. Muusa/ Ø-khu-wene líini}

Muusa/ SP-OP-see (perf) when

'when did Muusa see you?'- i.e. 'Muusa did not see you' 
g. wé/ Ø-uzile gaarí/ liiiní

you/ SP-buy (perf) car/ when

'when did you buy a car?'

Or: wé/ uzile liiní/ gáari

h. Núuru/ Ø-uzile líini/ gáari

Nuuru/ SP-buy (perf) when/ car

'Nuuru/ bought when/ a car?'

(Or: Núuru/ Ø-uzile gáari/ líini 'ibid.’

Or: Núuru/ gáari/ uzile líini 'ibid.'

Or: Gáari/ Núuru/ Ø-uzile líini 'ibid.’)

When pre-verbal, liini triggers pseudo-relativization, but not when post-verbal. It is ungrammatical to say: *Ali/ ilo liiní. Observe that liini, when located immediately after a verb, phrases with the verb. The examples (23c,d,g) show that liini is $[+F o c]$, since it triggers the ACCENTUAL LAW OF FOCUS and blocks final accent from projecting past it. While it is correct that *wé/ Ø-uzile liiní/ gaarí is unacceptable as an ordinary question, a final accent on gaari is possible if the speaker is seeking confirmation, e.g. that he heard correctly. (See our discussion of exclamatory yes-no questions below.)

When liini follows a complement to the verb, it is phrasally separated from that complement (23g,h).

\subsection{Nini-questions}

The last question word is nini 'what'. As we will see below, there is also an enclitic alternative to nini. nini only occurs in pre-verbal position and it triggers pseudo-relativization. In the following examples, it questions the subject of the verb.

a. níni/ i-vundishiló

what/ SP-break (perf, rel)

'what broke?'

b. níni/ i-poteeló

what/ SP-fall (perf, rel)

'what fell?' 
c. níni/ i-khu-peetó/ wé

what/ SP-OP-get (perf, rel) you

'what happened to you?'

d. níni/ ma'anaye

what/ its meaning

'what is the meaning (of what you said)?'

e. n-chhi-wa n-nazo peesá/ nini/ i-ta-ku-n-drebo k-ula gaarí

SP-cond-be SP-have money/ what/ SP-fut-inf-OP-stop inf-buy car

'if I have the money, what is it that will prevent me from buying a car?'

The data in (24), with the exception of (24d), show that nini triggers pseudorelativization of the verb. The example (24d) involves a zero form of the copula, thus there is no verb that can be put into a pseudo-relative form.

If nini questions the complement of the verb and is located in initial position, then it requires an - $\boldsymbol{a}$ link between it and the subject of the verb. The verb is in a pseudo-relative form.

a. níni/ y-aa wé/ Ø-tukiiló

what/ that you/ SP-carry (perf, rel)

'what are you carrying?'

\section{b. níni/ y-a Omári/ Ø-m-bozelo mw-aalimú}

what/ that Omari/ SP-OP-steal (perf, rel) teacher

'what is it that Omari stole from the teacher?'

Observe that nini is separated phrasally from the $\boldsymbol{A} \boldsymbol{G}-\boldsymbol{a}$ element that separates it from the subject of the verb. This phrasing suggests that nini is focused, since normally the element that is linked by the $\boldsymbol{A G}-\boldsymbol{a}$ to what follows forms a single phonological phrase (or at least may form such a phrase).

The question word nini may not be used in post-verbal position. For example, *wé/ Ø-tukilee niní or wé/ Ø-tukiilé/ níni are unacceptable. This limitation on nini leads us to a consideration of one of the enclitics used to form questions.

\subsection{Ni-enclitic}

One can asks the identity of an inanimate noun by cliticizing =ni to the verb. In the following examples, the encliticized verb is final in the VP and thus would 
be expected to be PP-final as a consequence of ALIGN-XP R. We thus cannot glean from these examples any evidence that the encliticized verb is a [+Foc] element.

(26)

a. $\quad$-uzíiza=ni

SP-sell (perf, pass)

'what was sold'

Possible answers:

y-uziza chi-búuku 'a book was sold' ([cl.9] subject agreement) or ch-uziza chi-búuku 'a book was sold’ ([cl.7] subject agreement)

b. Núuru/ Ø-bozelé=ni

Nuuru/ SP-steal (perf)=what

'what did Nuuru steal?'

c. n-faanye=ní

SP-do=what

'what shall I do?'

d. Jáama/ Ø-na-kh-fadhilá=ni

Jaama/ SP-pres-inf-prefer=what

'what does Jaama prefer?'

e. Jaama/ hu-kahata=ni

Jaama/ hab-dislike=what

'what does Jaama dislike?'

f. we/ Ø-tukiile=ní

you/ SP-carry (perf)=what

'what are you carrying?'

g. we/ Ø-na-kh-suula=ní

you/ SP-pres-inf-want=what

'what do you want?'

h. Ø-ile ku-meera=ní

SP-come (perf) inf-look for=what 'you came looking for what?' 
But what happens when the verb is followed by another word? The examples in

(27) illustrate the case where the following word is a postposed subject.

a. m-bozele=ní/ mí

SP-steal (perf)=what/ I

'what did I steal?'

b. Ø-bozelé=ni/ Núuru

SP-steal (perf)=what/ Nuuru

'what did he steal, Nuuru?' (*bozele=ni Núuru 'ibid.')

c. wa-talishiizá=ni/ w-áana

SP-make take (perf, pass)=what/ children

'what were they made to take, the children?'

d. Ø-hadiilé=ni/ sultáani

SP-say (perf)=what/ sultan

'what did the sultan say?'

e. Ø-fuzilé=ni/ Faatíma

SP-wash (perf)=what/ Faatima

'what did Faatima wash?'

A possible answer:

Ø-fuzilee n-gúwo/ Faatíma 'washed clothes, Faatima’

f. Ø-bozelé=ni/ maskíini

SP-steal (perf) =what/ poor man

'what did the poor man steal?'

A possible answer:

Ø-bozele péesa/ maskíini ‘stole money, the poor man’

g. Ø-fungiilé=ni/ m-íizi

SP-open (perf)=what/ thief

'what did he open, the thief?'

A possible answer:

Ø-fungile m-láango/ m-íizi 'opened the door, the thief'

These data show that the verb is in phrase-final position. If one could argue that the postposed subject is not part of the verb phrase, then one could argue that Align-XP $\mathrm{R}$ is responsible for the phrase edge at the end of the encliticized verb. 
This is a somewhat dubious claim, however, as there are examples showing that a subject postposed to the verb may be followed by other VP elements. Thus it seems more likely that the enclitic is [+Foc] and as a consequence of ALIGNFocus R, the verb is in phrase-final position.

Even stronger evidence for this claim comes from cases where the encliticized verb is followed by a complement.

a. Ø-m-peele=ní/ Núuru

SP-OP-give (perf)=what/ Nuuru

'you gave what to Nuuru?'

b. Núuru/ Ø-m-bozelé=ni/ m-áana

Nuuru/ SP-OP-steal (perf)=what/ child

'what did Nuuru steal from the child?'

(*Nuuru/ Ø-m-bozele=ni mw-áana,

where $\boldsymbol{m} \boldsymbol{w}$-aana is joined into a phrase with the verb).

c. Omári/ Ø-m-bozéle=ni/ mw-aalímu

Omari/ SP-OP-steal (perf)=what/ teacher

'what did Omari steal from the teacher?'

d. Ø-tinzile=ní/ kaa chí-su

SP-cut (perf)= what/ with knife

'what did you cut with a knife?'

(Or: kaa chí-su/ Ø-tinzile=ní)

e. Ø-teete=ní/ nthini y-a méeza

SP-take (perf)= what/ under of table

'what did you take from under the table?'

f. Hamádi/ Ø-patiliiilé=ni/ gáari

Hamadi/ SP-get for (perf)=what/ car

'what did Hamadi get for the car?'

g. Súufi/ Ø-m-patiliiléé=ni/ Núuru

Suufi/ SP-OP-get for (perf=what/ Nuuru

'what did Suufi get for Nuuru?'

In each of these examples, we see that the encliticized verb is phrasally separated from a following complement. When the verb is a final-accent trigger, 
as in (18a,d,e), we see that the final accent does not project past the enclitic. These data confirm the $[+$ Foc $]$ nature of the enclitic.

While =ni is typically encliticized to the verb of which it is an argument, when this verb is in a sentential complement, it is possible for the =ni to be raised to the higher verb.

a. wé/ Ø-hadile kuwa i-vundishile=ní

you/ SP-say (perf) that SP-break (perf)=what

'what did you say broke?'

but also:

b. wé/ Ø-hadiile=ní/ kuwa i-vundishíle

you/ SP-say=what/ that SP-broke (perf)

'what did you say that it broke?'

c. wé/ Ø-na-kh-tosha (kuwa) Nuurú/ Ø-bozele=ní

you/ SP-pres-inf-think (that) Nuuru/ SP-steal (perf)=what

'you thought that Nuuru stole what?'

but also:

d. wé/ Ø-na-kh-tosha=ní/ kuwa Núuru/ Ø-boozéle

you/ SP-pres-inf-think=what/ that Nuuru/ SP-steal (perf)

'what did you think that Nuuru stole?'

When the =ni remains on the lower verb, we have essentially an echo-type question. The sentence with the =ni raised to the higher verb is a simple question. When the enclitic is raised to the higher verb, it is obvious that the verb is phrase-final and the Accentual Law of Focus comes into play. The (b) and (d) sentences show that the sentential complement is not within the scope of final accent, in contrast with the (a) and (c) sentences. In none of the examples illustrated is the verb placed in a pseudo-relative form.

The $=$ ni is not necessarily encliticized to a verb. In the following example it is encliticized to the associative marker:

(30) nthini y-a=ni/ Ø-weshelo zi-buukú

under of=what/ SP-put (perf,rel) books

'under what did you put the books?'

Here we see a couple crucial points. First of all, the enclitic does not behave like a monosyllabic word (e.g. a pronoun). If it did, the vowel in the associative particle $\boldsymbol{y}$-a would be lengthened. But we also have to explain why $\boldsymbol{y}$-a=ni does not lengthen a preceding word-final vowel. Recall the discussion of gani earlier 
for similar behavior. The second point that needs to be mentioned is that since $\boldsymbol{y}$-a=ni is in pre-verbal position, the following verb is put into the pseudorelative form.

The =ni may also be cliticized to the preposition $\boldsymbol{k} \boldsymbol{a}$ to ask the question, 'with/by what' In pre-verbal position, the verb is in the pseudo-relative form.

a. Hamádi/ ká=ni/ Ø-oloshelo Mkhodiishó

Hamadi/ by=what/ SP-go (perf,rel) Mogadisho

'by what means did Hamadi go to Mogadisho?'

b. ká=ni/ wé/ Ø-oloshelo Mkhodiishó

by=what/ you/ SP-go (perf,rel) Mogadisho

'by what means did you go to Mogadisho?'

c. ká=ni/ Ø-tinziloo namá

with=what/ SP-cut (perf, rel) meat

'with what did you cut the meat?'

But in post-verbal position, $\boldsymbol{k a}=\boldsymbol{n} \boldsymbol{i}$ does not trigger pseudo-relativization.

a. Ø-tinzile ka=ní/ náma

SP-cut (perf) with=what/ meat

'what did you cut the meat with?'

Or: náma/ Ø-tinzile ka=ní

b. Ø-uzile ká=ni

SP-buy (perf) with=what

'what did he buy it with?'

c. wé/ Ø-oloshele ka=ní/ Mkhodíisho

you/ SP-go (perf) by=what/ Mogadisho

'you went by what means to Mogadisho?'

d. wé/ Ø-oloshele Mkhodiishó/ ká=ni

you/ SP-go (perf) Mogadisho/ by=what

'you went to Mogadisho by what means?' 
e. yé/ Ø-oloshele ká=ni/ Mkhoodisho

he/ SP-go (perf) by=what/ Mogadisho

'he went by what means to Mogadisho?'

Or: yé/ Ø-oloshele Mkhoodísho/ ká=ni

\section{f. Omári/ Ø-m-finishile mw-áana/ ká=ni}

Omari/ SP-OP-cover (perf) child/ with=what

'Omari covered the child with what?'

In (32b), the second person past tense form triggers final accent; however, the scope of the final accent cannot go past the focus element ka=ni. This explains why Mkhodiisho has default rather than final accent.

In (32d), notice that $\boldsymbol{k a} \boldsymbol{a}=\boldsymbol{n i}$ is not in the scope of the final accent of the verb. In Chimiini, immediate post-verbal position is the focus position for a verb complement. In (32d), the noun Mkhodiisho is focused and this focus triggers the Accentual Law of Focus, explaining why $\mathbf{k a = n i}$ is not included in the scope of the final accent triggered by the second person past tense verb.

The =ni may be encliticized to $\boldsymbol{k a}$ khisa to form the expression 'why; for what reason':

a. ka khísa=ni/ Súufi/ Ø-latililo i-ji-wé/ ch-olokoo=ní

for reason=what/ Suufi/ SP-throw (perf, rel) stone/ window=loc

'why did Suufi throw a stone/ at the window?'

b. Núuru/ nth-a-ku-ya ka khisá=ni

Nuuru/ neg-SP-inf-come for reason=what

'why didn't Nuuru come?'

Again, we see that in pre-verbal position, pseudo-relativization is triggered, but not in post-verbal position.

\subsection{Pi-enclitic}

In addition to the =ni enclitic, there is also an enclitic =pi ' where' which is attached to the verb. This enclitic puts the verb in PP-final position; we take this to be evidence that $=\boldsymbol{p} \boldsymbol{i}$ is $[+\mathrm{Foc}]$.

In the examples in (34), the verb is final in the VP (i.e. there are no complements) and thus the PP-final position of the verb is not necessarily attributed to the $[+\mathrm{Foc}]$ nature of the enclitic. 
(34)

a. Ø-na-k-eendra=pí

SP-pres-inf-go=where

'where are you going?'

b. ndó/ ni-m-latiile=pí

come/ SP-OP-throw (perf)=where

'come, where have you (pl.) thrown him?'

c. n-faanye=pí

SP-do=where

'where shall I do it?'

d. n-tha-kh-patá=pi

SP-fut-inf-get=where

'where will I get it?'

e. $\varnothing$-m-weene=pí

SP-OP-see (perf)=where

'where did you see him?'

(An appropriate answer: ni-mw-ene wowii=ní 'I saw him in the river'.)

In (35), however, the verb has a complement, but in the presence of the enclitic, the complement is not phrased with the verb.

(35)

a. Ø-weshele=pí/ zi-búuku

SP-put (perf)= where/ books

'where did you put the books?'

b. Ø-weshelé=pi/ zi-búuku

SP-put (perf)= where/ books

'where did he put the books?'

c. n-faanye=pí/ káazi

SP-do=where/ work

'where shall I work?' 


\section{d. n-tha-m-patá=pi/ nyúnyi/ mw-iingíne/ kama úyu}

SP-fut-OP-get=where/ bird/ another/ like this

'where will I get another bird like this one?'

In these two examples, we see that the enclitic =pi does not have any inherent accentual character. The verb form has final accent in the first example because the second person singular past tense verb is a final-accent trigger; in the second example, accent is penultimate since a third person past tense form has default accent. We know that the encliticized verb is the focus of the sentence because the complement zi-buuku stands in a separate phrase and is outside the scope of the final accent of the verb due to the Accentual Law of Focus which requires elements to the right of the focused verb to be outside the influence of the verb when it is a final accent-trigger.

In the following example, the encliticized verb is followed by a postposed subject. Once again, the verb is necessarily at the end of a phonological phrase due to the $[+\mathrm{Foc}]$ nature of the enclitic.

\section{(36) mbóna/ Ø-lazilé=pi/ maskíini}

say/ SP-come from (perf)=where/ poor man

'say, where did he come from, the poor man?'

The $=\boldsymbol{p i}$ enclitic does not trigger pseudo-relativization, presumably due to the fact that we have only observed it encliticized to the verb and thus it never occurs in the preverbal position that triggers pseudo-relativization.

\subsection{Yi-enclitic}

The next interrogative enclitic we will discuss is $=y \mathbf{i}$ 'how'. This enclitic is appended to the verb and due to its [+Foc] nature, places the verb in phrasefinal position. It also lengthens the vowel in front of it. This lengthening is not a unique property of the =yi enclitic. Two of the enclitics with the shape =ni (locative and plural marker in the imperative) also lengthen a preceding vowel.

In the examples in (37), =yi is appended to a verb that is located at the end of a VP, i.e. has no complement following it.

\section{a. chi-néema/ chi-walikóo=yi}

movie/ SP-was=how

'how was the movie?' 
b. Ø-fanyizée=yi

SP-do (perf)=how

'how did he do it?'

(cf. Ø-fanyizee=yí. 'How did you do it?')

c. Ø-oloshelée $=$ yi

SP-go (perf)=how

'how did he go?'

(cf. Ø-oloshelee=yí. 'How did you go?')

d. Ø-panzilee=yí

SP-climb (perf)=how

'how did you climb up?

e. Ø-ta-k-asháa=yi

SP-fut-inf-light=how

'how will he light it?'

When there is a complement to the verb, the [+Focus] nature of the encliticized verb forces the complement to be phrasally separated from the verb.

(38)

a. Ø-tinzilee=yí/ náma

SP-cut (perf)=how/ meat

'how did you cut/ the meat?'

b. Ø-tukilee=yí/ i-juuníya

SP-carry (perf)=how/ bag

'how did you carry the bag?'

c. Ø-uzilee=yí/ gáari

SP-buy (perf)=how/ car

'how did you buy/ a car?'

d. waawé/ wé/ Ø-na-kh-fanyaa=yí/ ku-na khámri.

my father/ you/ SP-pres-inf-do=how/ inf-drink liquor

'my father,why are you doing/ drinking liquor?'

We see from these examples that the presence of $[+\mathrm{Foc}]$ on the verb precludes a final-accent trigger verb from imposing its final accent on the complement. 
The =yi enclitic does not trigger pseudo-relativization, presumably due to the fact that we have only observed it encliticized to the verb and thus it never occurs in the preverbal position that triggers pseudo-relativization.

\section{Yes-no questions}

Yes-no questions preserve the phrasing of their corresponding statements, as far as we can discover at present. As such, they do not contribute anything to the principles of phrasing in Chimwiini. However, any study of phrasing in Chimwiini is a study of the phonology of phrases - specifically, the issues of stress (i.e. the realization of vowel length) and accent. While we have not noted yes-no questions having any effect on vowel length, it turns out that they have significant impact on accent. It is this impact that we will explore here.

There are two types of yes-no question with different prosodic properties. One type we refer to as "simple" yes-no questions. They ask whether something did or did not occur. The second type is referred to as "exclamatory": they express surprise that something has or has not occurred, or seek confirmation.

\subsection{Simple yes-no questions}

Simple yes-no questions are characterized first and foremost by raised pitch in comparison to the corresponding statements. The precise nature of this raising is not a trivial matter, and the two speakers for whom we have data depart to some extent in details. We indicate the raising of simple yes-no questions by writing a superscript ${ }^{\mathrm{i}}$ in front of sentences of this type.

The sentences in (39) illustrate statements that have no focused element. In the statements, there is what we shall refer to as "downstep" intonation: the initial accent is the peak pitch in the sentence, and each successive accented syllable is lowered in pitch. The simple yes-no question does not exhibit this downstepping, a critical aspect of the Q-raising associated with simple yes-no questions. (We should note that a final accent in Chimwiini typically has a falling character to it, but we do not ordinarily indicate this in our transcription. However, in yes-no questions, this falling character is quite prominent and we

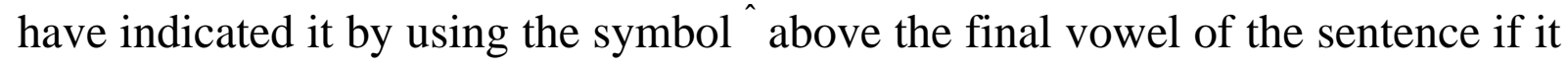
is accented. 
(39)

a. Bázi/Ø-m-pele mw-áana/ khalámu

Bazi/ SP-OP-give (perf) child/ pen

'Bazi gave the child a pen'

${ }^{Q}$ Bázi/ Ø-m-pele mw-áana/ khalámu?

'did Bazi/ give the child/ a pen?'

b. Núuru/ Ø-pakize gáari/ ma-jíwe

Nuuru/ SP-load (perf) truck/ stones

'Nuuru loaded the truck with stones.'

${ }^{\mathbf{Q}}$ Núuru/ pakize gáari/ ma-jíwe?

did Nuuru/ load the truck/ with stones

c. mw-aalímu/ Ø-m-andikilile mw-áana/ kháti teacher/ SP-OP-write for/to (perf.) child/ letter 'the teacher wrote a letter for/to the child'

${ }^{\mathrm{Q}} \mathrm{mw}$-aalímu/ Ø-m-andikilile mw-áana/ kháti?

'did the teacher write to/for the child/ a letter?'

d. Háaji/ Ø-m-ulile mw-áana/ m-phúundra

Haaji/ SP-OP-buy for (perf)/ donkey

'Haaji bought a donkey for the child'

${ }^{Q}$ Háaji/ Ø-m-ulile mw-áana/ m-phúundra?

'did Haaji buy for the child/ a donkey?'

e. mí/ n-jilee namá

I/ SP-eat (perf) meat

'I ate meat'

Qmí/n-jilee namâ? 'did I eat meat?’

f. sí/ chi-m-bozele mw-aalimú/ chi-buku ch-a hisaabú

we/ SP-OP-steal (perf) teacher/ book of arithmetic

'we stole from teacher an arithmetic book'

Q sí/ chi-m-bozele mw-aalimú/ chi-buku ch-a hisaabû?

'did we steal from teacher an arithmetic book?'

In these data, the phrasing in the question is the same as the phrasing in the corresponding statement. Furthermore, the location of the accent in each phrase in the question is the same as the accent location in the statement. Thus, if a phrase has final accent in the statement, as in $(39 \mathrm{e}, \mathrm{f})$, then it has final accent in the question as well. 
If, however, the verb is focused, we get a surprising result. Before looking at the relevant data, we should note that when a word is focused, it is raised in pitch and thus the usual downstep intonation does not hold for this element. We indicate this raised pitch below by locating the symbol ${ }^{\mathbf{R}}$ at the beginning of the affected phrase. (We did not, of course, indicate this raised pitch earlier in the paper since it was irrelevant to the discussion.)

a. yé/ ${ }^{\mathrm{R}} \emptyset$-jíile/ náma

he/ SP-eat (perf)/ meat

'he ate meat.'

${ }^{\mathbf{Q}} \mathbf{y e ́} /{ }^{\mathrm{R}} \emptyset$-jíile/ namâ? 'did he eat meat?'

b. Omári/ ${ }^{\mathrm{R}}$ nth-a-kh-póowa/ chi-búuku

Omari/ neg-SP-inf-give (pass)/ book

'Omari was not given a book'

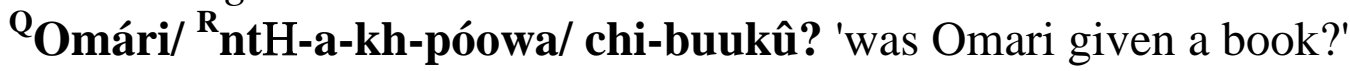

c. mí/ ${ }^{\mathrm{R}}$ n-thiinzilé/ náma/ kaa chí-su

I/ SP-cut (perf)/ meat/ with knife

'I cut the meat with a knife'

${ }^{\mathbf{Q}} \mathbf{m i ́} /{ }^{\mathrm{R}} \mathbf{n}$-thiinzilé/ namá/ kaa chi-sû?

'did I cut the meat with a knife?'

\section{d. Hasáni/ ${ }^{\mathrm{R}}$ Ø-furahíile/ kh-pata péesa}

Hasani/ SP-be pleased (perf)/ inf-get money

'Hasani was pleased to get money'

${ }^{\mathbf{Q}}$ Hasáni/ ${ }^{\mathbf{R}}$ Ø-furahíile/ kh-pata peesâ?

'was(n't) Hasani pleased to get the money?'

What these data clearly show is that the out-of-focus verb complement is assigned final rather than the default penult accent! In the corresponding statements, the out of focus complement always has default accent since the focus on the verb prevents any final accent that the verb might trigger from projecting beyond the verb (due to the Accentual Law of Focus). The yes-no question, thus, completely reverses the tonal shape, putting final accent on the out-of-focus complement. We refer to this phenomenon as accent shift.

When a verb has two complements, and the first complement is focused, then the second complement undergoes accent shift in the yes-no question. 
(41) sí/ ${ }^{\mathrm{R}}$ chi-m-bozele m-aalimú/ chi-buku ch-a hisaabu

we/ SP-OP-steal (perf) teacher/ book of arithmetic

'we stole from the teacher an arithmetic book'

${ }^{\mathbf{Q}}{ }_{\text {sí/ }}{ }^{\mathbf{R}}$ chi-m-bozele mw-aalimú/ chi-buku ch-a hisaabû?

'did we steal from the teacher an arithmetic book?'

In the statement, the verb is a final accent-trigger and thus a final accent appears at the end of the first complement. However, since the first complement is focused, the final accent may not project past it onto the second complement. However, in the yes-no question, the second complement undergoes accent shift and receives a final $\mathrm{H}$ tone.

When an XP is preposed, however, it is not subject to accent shift in the simple yes-no question, but instead is assigned default accent. This indicates that preposing is not used to put an XP out of focus.

a. wó/ ${ }^{\mathrm{R}}$ chi-buku ch-a hisáabu/ wa-m-bozele m-aalímu

they/ book of arithmetic/ SP-OP-steal (perf) teacher

'the arithmetic book, they stole it from the teacher'

${ }^{\mathrm{Q}}$ wó// ${ }^{\mathrm{R}}$ chi-buku ch-a hisáabu/ wa-m-bozele m-aalímu?

'did they steal the arithmetic book from the teacher?'

\section{b. kaa chí-su/ náma/ yé/ Ø-tiiinzíle}

with knife/ meat/ ye/ SP-cut (perf)

'with a knife he cut meat'

${ }^{\mathrm{Q}}$ kaa chí-su/ náma/ yé/ ${ }^{\mathbf{Q}}$ Ø-tiiinzíle? ‘did he cut meat with a knife?’

When a subject is postposed after a verb, the postposed subject in the yes-no question undergoes accent shift.

a. Ø-léele/ mw-ana w-a Halíima

SP-sleep (perf)/ child of Haliima

'slept, did Halima's child'

Q-leele/ mw-ana w-a Haliimâ?

b. Ø-tezéeze/ Núuru

SP-play (perf)/ Nuuru

'played, Nuuru did'

Q Ø-tezéeze/ Nuurû? 
In these examples, the postposed subject is phrased separately from the verb and the simple yes-no question shows that it is treated the same as the out-of-focus elements discussed in (40): the accent is shifted to the final syllable.

It is possible for a postposed subject to be phrased with the verb. In this case, the postposed subject is not out-of-focus and does not shift its accent.

a. Ø-pela Omári/ chi-búuku

SP-give (perf, pass) Omari/ book

'Omari was given a book.'

QØ-pela Omári/ chi-buukû? 'was Omari given a book?'

b. wa-pikilila w-áana/ máangi

SP-cook for (perf, pass) children/ beans

'the children had beans cooked for them'

Qwa-pikilila w-aana/ maangî?

'did the children have beans cooked for them?'

\subsection{Exclamatory yes-no questions}

The exclamatory yes-no questions show a more extensive shift to final accent than do simple yes-no questions, a shift that is unconnected to focus. The phonetics of these questions is interesting. Like canonically phrased sentences in general, they show a downstep intonation. They differ from statements, however, in certain significant ways. In the speech of Mohammad Imam, they are systematically lower in the pitch register than the corresponding statements. This feature is not so clear in the speech of my current consultant, though he also seems to have special intonational features associated with the exclamatory questions. In any case, both speakers agree in that whereas in statements, a focused element is raised in pitch, this raising disappears in the exclamatory questions. Downstep occurs independently of the presence of focus or emphasis.

A particularly striking feature of exclamatory questions is that the accent is shifted to the final syllable in all phonological phrases in the VP, and also in preverbal position (although this seems to be a more variable phenomenon as far as our current understanding goes). Note that we have prefaced the exclamatory questions with a downward-pointing arrow to indicate the downstep intonation, and there is no use of the ${ }^{\mathrm{R}}$ symbol since raising is not employed. 
(45)

a. mw-ana w-a Halíima/ Ø-íle

child of Haliima/ SP-come (perf)

'Haliima's child came'

simple yes-no question: ${ }^{\mathbf{Q}} \mathbf{m w - a n a}$ w-a Halíima/ Ø-íle?

exclamatory yes-no question: ${ }^{\downarrow}$ mw-ana w-a Haliimá/ Ø-ilê!?

b. yé/Ø-jilee náma

he/ SP-eat (perf) meat

'He ate meat.'

simple yes-no question: ${ }^{\mathbf{Q}}$ yé/ Ø-jilee náma?

exclamatory yes-no question: ${ }^{\downarrow}$ yé/ Ø-jilee namâ!?

c. Bazi/ Ø-m-pele m-áana/ khalámu

Bazi/ SP-OP-give (perf) child/ a pen

'Bazi gave the child a pen'

simple yes-no question: $\quad$ QBázi/ Ø-m-pele mw-áana/ khalámu?

exclamatory yes-no question: ${ }^{\downarrow}$ Bázi/ Ø-m-pele mw-aaná/ khalamû!?

d. Nuuru/ Ø-pakize gáari/ ma-jíwe

Nuuru/ SP-load (perf) truck/ stones

'Nuuru loaded the truck with stones.'

simple yes-no question: $\quad{ }^{\mathbf{Q}}$ Núuru/ Ø-pakize gáari/ ma-jíwe?

exclamatory yes-no question: ${ }^{\downarrow}$ Núuru/ Ø-pakize gaarí/ ma-jiwê!?

e. Núuru/ Ø-m-bishile mw-ana w-a Halíima

Nuuru/ SP-OP-beat (perf) child of Haliima

'Nuuru beat Halima's child.'

simple yes-no question: ${ }^{\mathbf{Q}}$ Núuru/ m-bishile mw-ana w-a Halíima?

exclamatory yes-no question: ${ }^{\downarrow}$ Nuurú/ m-bishile mw-ana

w-a Haliimâ!?

If the verb is focused, then subsequent complements have final accent (as in the simple yes-no question), but so does the verb itself (in contrast to the simple yesno question).

a. yé/ ${ }^{\mathrm{R}}$ Ø-jíile/ náma

he/ SP-eat (perf)/ meat

'he ate meat' 
simple yes-no question: $\quad$ Q yé/ Ø-jíile/ namâ?

exclamatory yes-no question: ${ }^{\downarrow}$ yé/ Ø-jiilé/ ñamâ!?

b. yé/ ${ }^{\mathrm{R}}$ Ø-tiiinzíle/ náma/ kaa chí-su

he/ SP-cut (perf)/ meat/ with knife

'he cut meat with a knife'

simple yes-no question: $\quad{ }^{\mathbf{Q}}{ }{ }^{\prime} /{ }^{\mathrm{R}}$ Ø-tiinzíle/ namá/ kaa chi-sû?

exclamatory yes-no question: ${ }^{\downarrow}$ yé/ Ø-tiinzilé/ namá/ kaa chi-sû!?

A preposed complement shifts its final accent in the exclamatory yes-no question, unlike the simple yes-no question. Of course, the other elements in the sentence also undergo accent shift.

a. wó/ ${ }^{\mathrm{R}}$ chi-buku ch-a hisáabu/ wa-m-bozele mw-aalímu

they/ book of arithmetic/ SP-OP-steal (perf) teacher

'they stole the arithmetic book from the teacher'

simple yes-no question: ${ }^{\mathbf{Q}}$ wó/ chi-buku ch-a hisáabu/ wa-m-bozele mw-aalímu?

exclamatory yes-no question: ${ }^{\downarrow}$ wó/ chi-buku ch-a hisaabú/

wa-m-bozele mw-aalimû!?

b. kaa chí-su/ náma/ yé/ Ø-tiinzíle

with knife/ meat/ he/ SP-cut (perf)

'with a knife he cut meat'

simple yes-no question: $\quad$ Q $\quad$ kaa chí-su/ náma/ yé/ Ø-tiinzíle?

exclamatory yes-no question: ${ }^{\downarrow}$ kaa chi-sú/ ñamá/ yé/ Ø-tiinzilê!?

A postposed subject in the exclamatory question of course undergoes accent shift, just as does the phrase containing the verb. In contrast, in the simple yesno question, only the out-of-focus complement undergoes accent shift:

a. Ø-léele/ mw-ana w-a Halíima

SP-sleep (perf)/ child of Haliima

'slept, did Halima's child'

simple yes-no question:

exclamatory yes-no question:

Q Ø-léele/ mw-ana w-a Haliimâ?

Ø-leelé/ mw-ana w-a Haliimâ!? 


\section{b. Ø-tezéeze/ Núuru}

SP-play (perf)/ Nuuru

'played, Nuuru did'

simple yes-no question: $\quad \quad \quad \quad$ Ø-tezéeze/ Nuurû?

exclamatory yes-no question: ${ }^{\downarrow} \emptyset$-tezeezé/ Nuurû!?

\section{Conclusion}

In Wh-questions, all question words or enclitics show evidence that they are specified as [+Foc] and trigger application of Align-Foc R. If a question word or enclitic is pre-verbal, it triggers pseudo-relativization of the verb. If the question word or enclitic is post-verbal, then pseudo-relativization does not occur. There are no question words or enclitics in the yes-no questions we considered in section 3, and thus there is nothing to trigger Align-Foc $\mathrm{R}$ or pseudorelativization. Simple yes-no questions show that out-of-focus complements trigger final accent. In exclamatory yes-no questions, the shift to final accent is more general and not restricted to out-of-focus complements. In these cases, accent shift simply signals the exclamatory nature of the question.

\section{References}

Kisseberth, C.W. 2005. Accent and phrasing in Chimwiini. In: Kaji, S. (Ed.), Proceedings of the symposium: Cross-linguistic studies of tonal phenomena, 129-145. Research Institute for Languages and Cultures of Asia and Africa (ILCAA). Tokyo University of Foreign Studies, Tokyo.

Kisseberth, C. W. (2010a) Optimality theory and the theory of phonological phrasing: the Chimwiini evidence. In: Erteschik-Shir, N., Rochman, L. (Eds.). The sound pattern of syntax. Oxford University Press: Oxford and New York, 217-246.

Kisseberth, C. W. (2010b) Phrasing and relative clauses in Chimwiini. In: Downing, L., Rialland, A., Beltzung, J-M., Manus, S., Patin, C., Riedel, K. (Eds.), ZAS Papers in Linguistics 53: 109-144.

Kisseberth, C. W., Abasheikh, M. I. (1974) Vowel length in Chi Mwi:ni - a case study of the role of grammar in phonology. In: Bruck, A., Fox, A., La Galy, M.W. (Eds.), Papers from the Parasession on Natural Phonology, 193-209. Chicago Linguistic Society, Chicago.

Kisseberth, C. W., Abasheikh, M. I. (2004) The Chimwiini Lexicon Exemplified. Asian and African Lexicon no.45: Research Institute for Languages and Cultures of Asia and Africa (ILCAA), Tokyo University of Foreign Studies, Tokyo.

Kisseberth, C.W. and M.I. Abasheikh. (In press) Chimwiini Phrasing Revisited. Lingua special issue, The phonology and syntax interface.

Selkirk, E. (1986) On derived domains in sentence phonology. Phonology Yearbook 3: 371405. 